\title{
Parametric Geometry Models for Hypersonic Aircraft: Integrated External Inlet Compression
}

\author{
Konstantinos Kontogiannis ${ }^{\dagger}$ \\ University of Southampton
}

\author{
Nigel Taylor* \\ MBDA UK, Filton
}

\author{
András Sóbester ${ }^{\S}$ \\ University of Southampton
}

In this paper we are investigating a method for the design and integration of $3 \mathrm{D}$ external compression inlet geometries on parametric geometries of air-breathing hypersonic aircraft. We view the geometries as the first stage of a mixed compression inlet. The investigations are based on waverider geometries generated with the osculating cones waverider forebody design method. The osculating cones method is further utilized to create a second compression surface before the inlet cowl, essentially creating a second waverider geometry on the underside of the forebody. This way, we achieve greater compression for the part of the flow to be captured by the inlet cowl using a geometry that does not require sidewalls (like 2D ramps do), and has a potentially larger capture area than axisymmetric inlet geometries such as half-cones. The integration method is explained in detail, validated and further examined with CFD simulations. Those include measurements of the sensitivity of the flowfield to angle of attack, sideslip and Mach number changes. A number of options for designing the downstream internal compression part of the inlet are also discussed.

\section{Nomenclature}

$\begin{array}{ll}\text { CFD } & =\text { Computational Fluid Dynamics } \\ \text { ICC } & =\text { Inlet Capture Curve of the compression geometry } \\ \text { LSPC } & =\text { Lower Surface Profile Curve } \\ M_{\text {inf }} & =\text { freestream Mach number } \\ \mathrm{R}_{\mathrm{c}} & =\text { radius of curvature } \\ \mathrm{SWPC} & =\text { Shockwave Profile Curve of the forebody } \\ \mathrm{USPC} & =\text { Upper Surface Profile Curve } \\ \alpha & =\text { local osculating plane inclination } \\ \theta_{c} & =\text { local osculating cone half angle } \\ \theta_{d e f} & =\text { forebody shockwave deflection angle } \\ \theta_{s} & =\text { forebody shockwave angle } \\ \theta_{i n} & =\text { inlet shockwave angle }\end{array}$

\section{Introduction}

W AVERIDER geometries are one of the most promising aircraft configurations that are being considered for hypersonic air-breathing flight due to their superior aerodynamic performance. Waveriders are lifting body geometries designed to keep the shockwave generated by the oncoming hypersonic flow attached to the entire leading edge, effectively trapping the high-pressure region behind the shockwave at the underside of the body, greatly increasing the lift. Since their introduction, inverse design methods have been extensively used to generate such geometries ${ }^{1-4}$, usually based on planar or axisymmetric flowfields. One of the later and more flexible inverse design methods for generating waverider and inlet geometries is the osculating cones method ${ }^{5}$, which has also been further developed to allow greater flexibility in defining the shock generating body on each osculating plane ${ }^{6-7}$. Although the osculating cones and similar inverse design methods are, by themselves, not sufficient for producing realistic and complete hypersonic aircraft geometries, they provide a great tool for rapidly and efficiently generating geometries with a leading edge attached shock which can form the starting point of higher fidelity design processes.

\footnotetext{
${ }^{\dagger}$ Postgraduate Research Student, University of Southampton, Boldrewood Campus, Southampton, UK, SO16 7 QF.

* Capability Leader Aerodynamic Tools \& Methods, MBDA, PO Box 5, Filton, UK, BS34 7QW; SMAIAA.

$\S$ Associate Professor, University of Southampton, Boldrewood Campus, Southampton, UK, SO16 7QF; SMAIAA.

Page 1 of 11

American Institute of Aeronautics and Astronautics
} 
One of the dominant characteristics of hypersonic air-breathing aircraft designs is the level of integration between the airframe and propulsion system, something that adds to the complexity of design/optimization studies and emphasizes the need for efficiently parameterized geometry models, the development of which has been the focus of our work ${ }^{8-9}$. The engine inlet, with compression usually starting at the leading edge of the forebody, is what defines the scramjet characteristics and flowpath. Over the years a variety of scramjet inlet configurations have been proposed $^{10}$. The majority of scramjet test beds have, so far, utilized 2D mixed compression inlets, mostly due to the simplicity and robustness of the design, even when operating at off-design conditions. When using 2D compression ramp geometries, the flow being externally compressed needs to be contained with sidewalls before the cowl lip or significant spillage occurs, something that either way results in added viscous or spillage losses. There are a number of geometries that achieve 3D compression, such as Busemann-type or inward turning inlets and shock-cones or half shock-cones, the latter usually found on supersonic aircraft. Inward-turning Busemann-type inlets are generally more sensitive to deviations from design conditions and have also been the subject of various studies looking into both their design and integration on hypersonic aircraft.

The external inlet compression geometry, whose integration on a waverider forebody we are investigating, is essentially the external compression stage of a mixed compression inlet. It has the advantage of not requiring sidewalls to contain the externally compressed flow, while also enabling larger capture areas than that of an axisymmetric half-cone inlet attached to the underside of the waverider, due to its flexibility in defining the shape of the compression shockwave. In the present work we are essentially integrating an osculating cones derived inlet compression geometry on an osculating cones designed waverider forebody, while keeping the entire integration process parametric. It is worth noting that the osculating cones method itself was developed with inlet design in mind. At this stage we have been mostly using the osculating cones method for both, though the osculating axisymmetry $^{3}$ and osculating flowfield ${ }^{4}$ extensions of the method can potentially further improve the configuration. After describing the geometry generation process, we will look into how it can be integrated onto waverider forebodies generated with inverse design methods. We will then proceed to validate the geometry and evaluate its performance with CFD simulations. That will include investigations into the sensitivity of the resulting flowfield to variations of angle of attack, sideslip and freestream Mach number. Finally, we discuss some of the options currently under investigation for the downstream internal part of the inlet geometry, from the cowl lip up to the isolator of the scramjet.

\section{Background}

The osculating cones method is a supersonic compression geometry inverse design algorithm proposed by Sobieczky in $1990^{5}$. The method utilizes the axisymmetric flowfield of a shock-generating cone in supersonic flow, whose properties can be calculated by numerically integrating the Taylor-McColl equations ${ }^{13}$. That flowfield solution is then applied on planes along the span in a non-axisymmetric manner. The design is driven by a curve controlling the shockwave shape, usually by defining its trace at the base plane, and another curve from which the shape of the leading edge on the shockwave can be designed.

Starting with she shockwave profile curve and given a shock angle, the 3D shape of the shock surface is fully defined. The flowfield solution is then applied to planes perpendicular to the local shockwave profile, while being scaled appropriately so that the local conical shockwave matches the curvature of the prescribed shock profile on each plane, as seen in Figure 1. The leading edge trace (point 3) on each osculating plane can be calculated given the traces of the two design-driving curves on the plane (points 1 and 2). The lower surface of the waverider is then generated by tracing the streamlines of the flowfield on each plane from the leading edge to the base plane, from point 3 to 4 in Figure 2. As the stream-surface is replaced with a solid boundary, the flowfield downstream of the leading edge is replicated by the generated geometry alone. The upper surface is usually set to be parallel with the oncoming flow, although its shape can be manipulated to further improve aerodynamic characteristics or to create more space for the packaging of internal subsystems.

The osculating cones method essentially enforces a locally conical flowfield in the series of planes along the span of a non-conical shockwave, therefore the resulting flowfield is not an exact solution but a very good approximation, as small pressure gradients across different planes can cause some limited cross-flow. The effect of the cross-flow pressure gradients has been investigated ${ }^{11}$, and applicability of the method has been experimentally validated $^{12}$. 


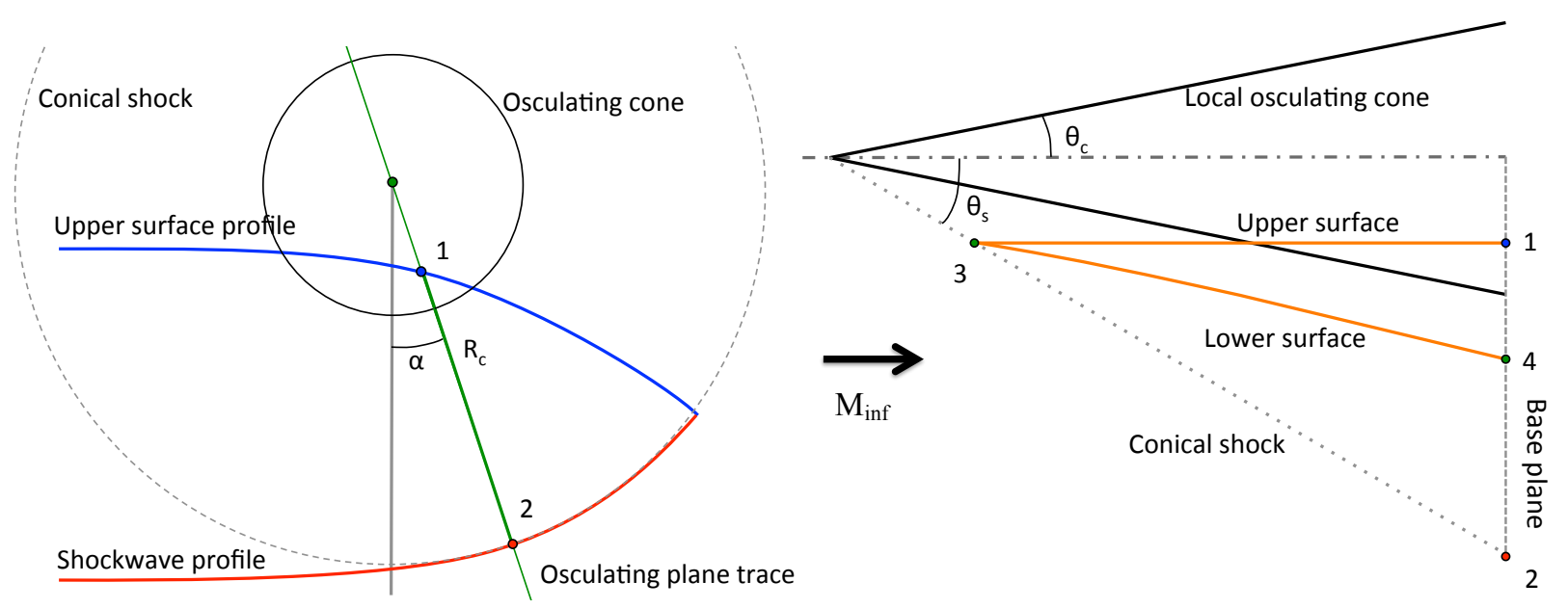

Figure 1. Single osculating plane (green trace) features on the base plane.

Figure 2. Waverider design on a single osculating plane.

The osculating axisymmetry ${ }^{6}$ and osculating flowfield ${ }^{7}$ extensions of the method introduce some additional flexibility to the design by adding further control over the shape of the shock and flowfield generating body on each plane. This enables a wider range of flowfields that can vary along the different sections of the waverider, something that can be utilized to improve flow compression in selected sections or further control the generated flowfield.

\section{Integrated External Inlet Compression Geometry}

The osculating cones method, given its flexibility in prescribing the shockwave shape and ability to generate 3D compression geometries where the flow properties can be calculated with little computational cost, provides an excellent tool for the generation of not only waverider forebody geometries, but inlet geometries as well. When using an osculating cones generated geometry for the inlet we need to consider that the design method assumes that the oncoming flow is uniform in order to replicate the prescribed flowfield. This is obviously no issue for the waverider forebody geometry since that is always the case for the freestream flow. The inlet compression geometry, however, is behind the initial shock generated by the forebody. Therefore, in order to integrate the compression geometry on the underside of the waverider forebody, at least part of the flow behind the forebody shock needs to be uniform. That condition is met for planar shock based inverse design techniques but not for most axisymmetric ones, such as conical shock waveriders. The osculating cones/flowfield generated geometries can satisfy that condition when the radius of curvature of the shock is locally infinite (no curvature). Therefore, by using a straight line segment for part of the shockwave profile of the waverider forebody, we generate a uniform flow region within which the second, inlet compression geometry can be designed. The parametric design-driving curves of an osculating cones waverider forebody with that feature, as well as the inlet capture curve (ICC) of the external compression geometry drawn within its uniform flow region are illustrated in Figure 3.

To design the inlet geometry, the inflow conditions for the osculating cones/flowfield inverse design algorithm are set to be the flow conditions behind the forebody-generated shock, which is planar in that region. The axis of the local axisymmetric osculating flowfields is tilted relative to the freestream at an angle equal to the deflection angle $\left(\theta_{d e f}\right)$ of the planar shock of the forebody, illustrated in Figure 4. The lower surface profile of the waverider at that part of the geometry becomes the upper surface profile curve for the inlet compression geometry. The ICC can then be drawn using a parametric curve; we used a $4^{\text {th }}$ order Bézier curve in this example. The first end point on the symmetry plane should be placed within the region of the forebody-generated shockwave where the flow is uniform. Placing the other end point of the ICC at the edge of the uniform flowfield maximizes the inlet's capture area. A shock angle is chosen for the ICC defined shock and the method from then on is followed as usual to generate the external compression geometry of the inlet.

As was stated in our previous work $^{8}$, designing the forebody shockwave profile curve using a line segment followed by a parametric curve can result in discontinuities or sharp edges present on the resulting surfaces, unless third order continuity of the shockwave profile curve is maintained at the interface. In this case, this is accomplished by having the three consecutive intermediate points of the Bézier curve that was used on the same line.

Page 3 of 11

American Institute of Aeronautics and Astronautics 


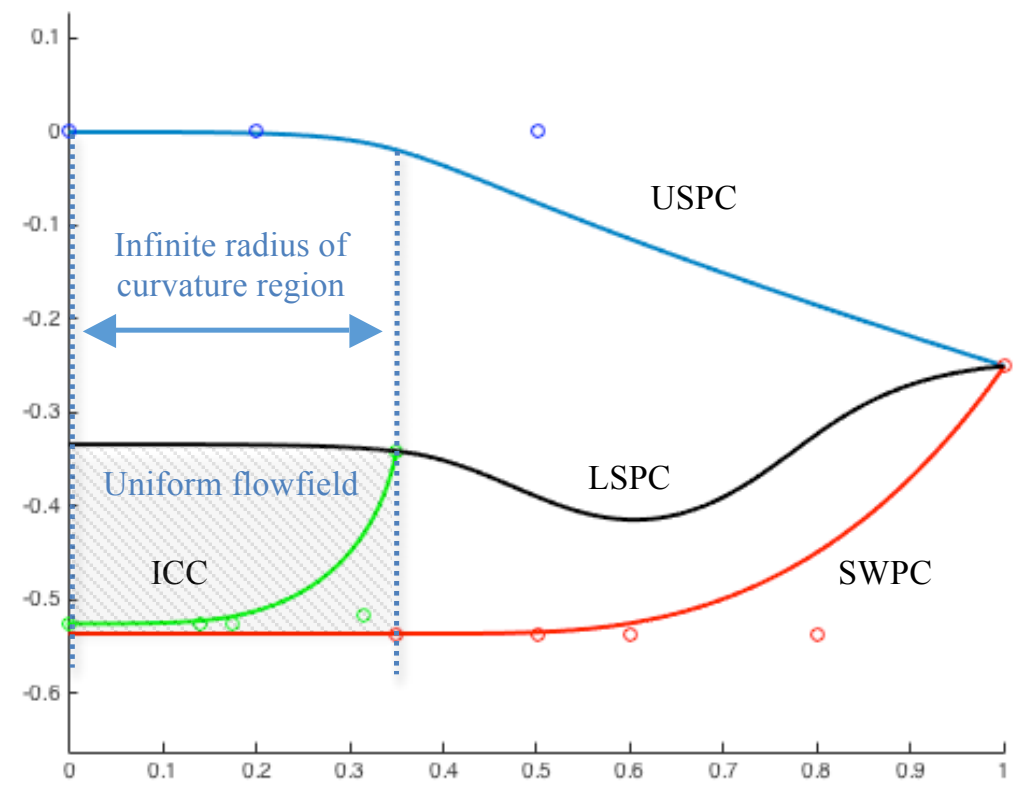

Figure 3. Osculating cones forebody and inlet design-driving curves with their control points.

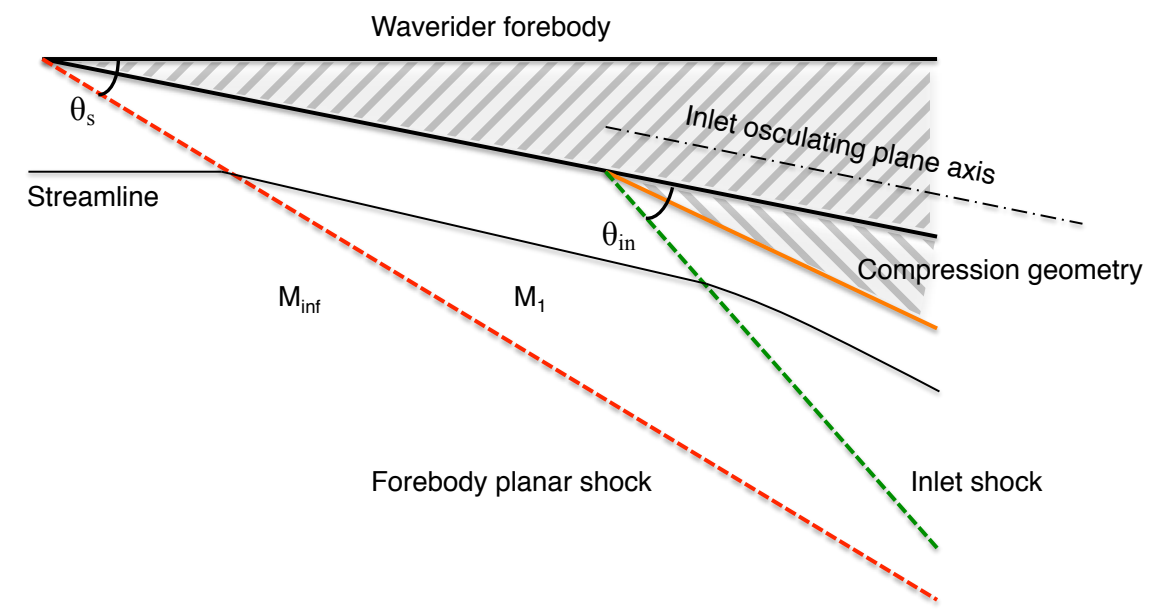

Figure 4. Key flow features of the external inlet geometry, symmetry plane section.

The final geometry generated in the manner described above, corresponding to the design curves of Figure 3, can be seen in Figure 5. It is a Mach 8 design with both the forebody and inlet shock angled at $15^{\circ}$. Some of the Euler CFD results to validate the resulting flowfield are shown in Figures 6 and 7. The CFD values are compared with the ones obtained through the design algorithm that utilizes the Taylor-Maccoll equations. According to the results of the inviscid simulations as well as the values obtained from the design algorithm, the Mach numbers within the externally compressed region of the flowfield range from 4.84 to 4.95 due to the nature of the conical flowfield. Additionally, all streamlines of the externally compressed flow, contained by the inlet capture curve at the end section seen in Figure 7, traverse two deflections/shocks of equal strength.

As mentioned earlier, the osculating cones method itself has been proposed as a method to design inlet geometries as well as waverider forebodies. In this section we have presented a method to integrate an osculating cones generated inlet compression geometry onto an osculating cones generated waverider in a parametric manner. This enables us to prescribe a second shock shape where a cowl lip can be placed to capture the flow that has been further externally compressed. Additionally, the flowfield properties at the section of the cowl lip can be rapidly calculated through the inverse design method's flowfield calculations, the Taylor-Maccoll equations in this case. This can further aid with the design of the downstream internal part of the inlet. 
Compression geometry interface/Origin of compression shockwave

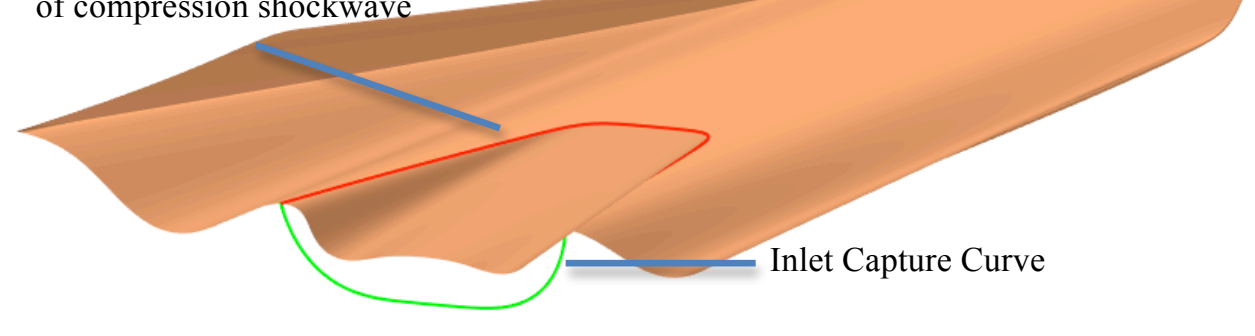

Figure 5. External compression inlet geometry on waverider forebody with the outline of the compression shockwave.

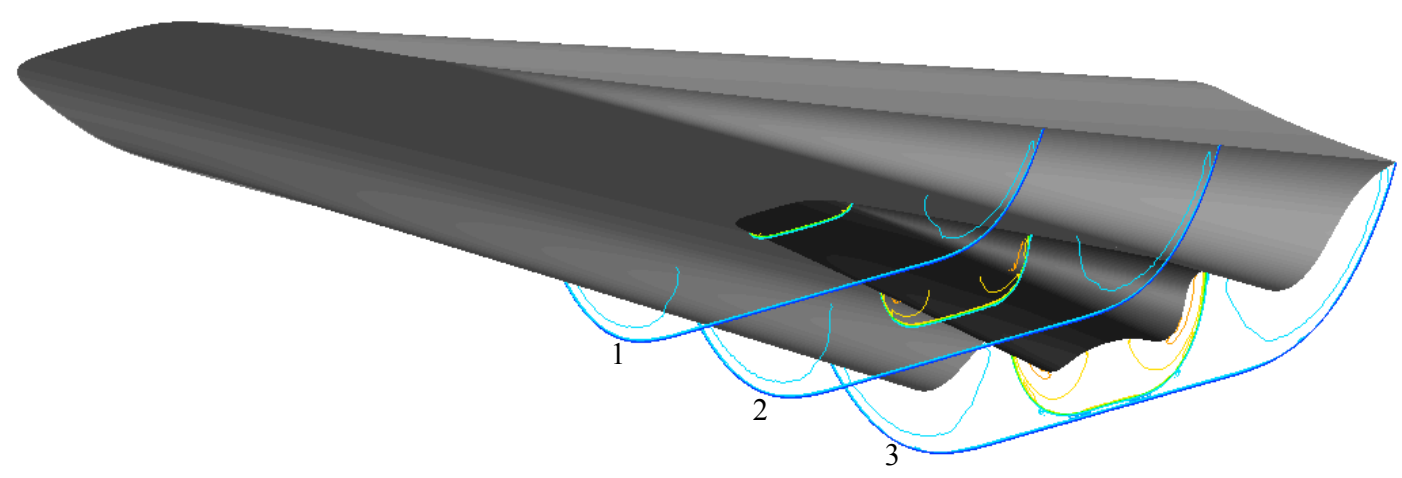

Figure 6. Static pressure iso-lines around the inlet compression geometry on three y-z planes, Euler CFD results.

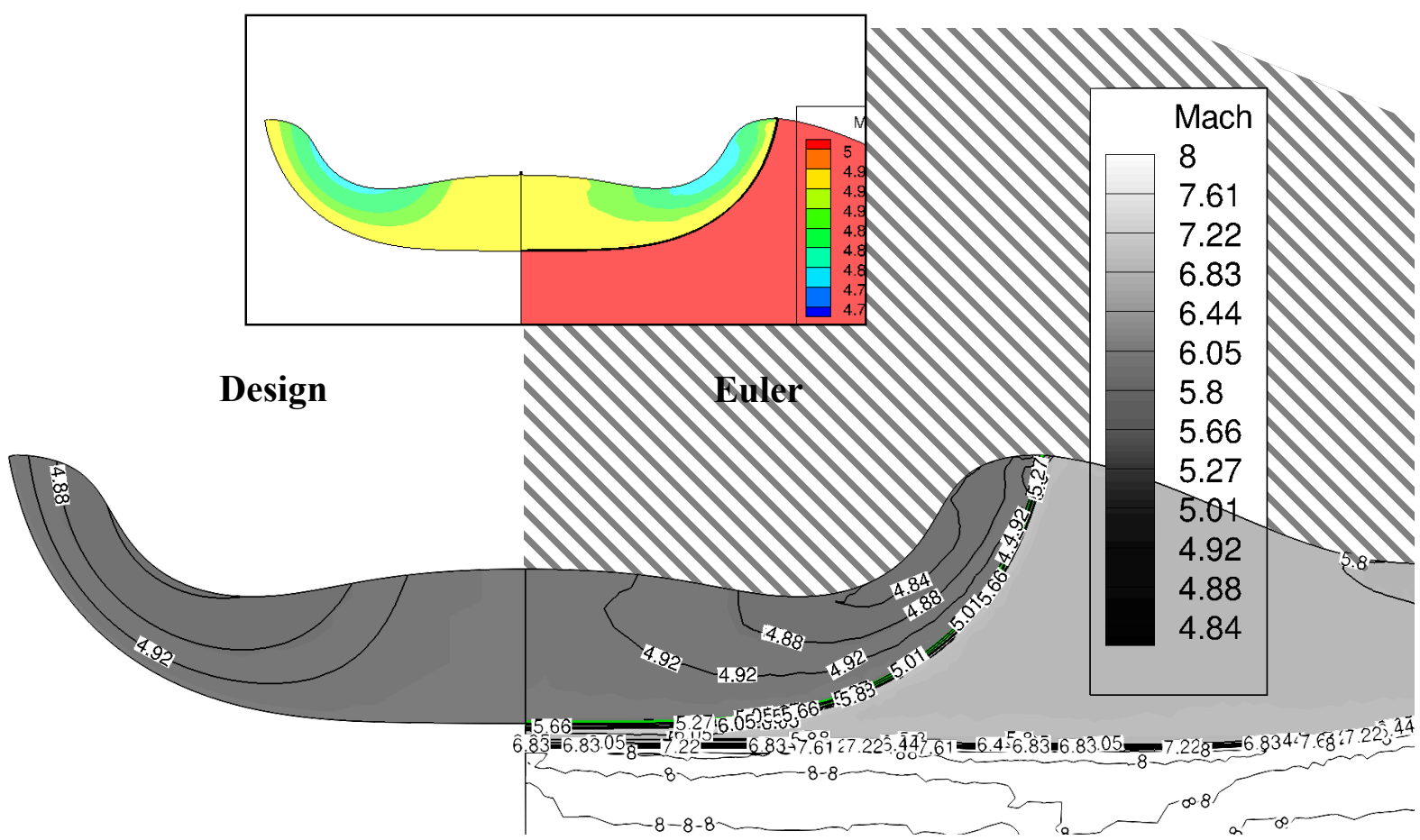

Figure 7. Mach number contour comparison between design and Euler CFD of the further compressed flow at the base/exit plane, $M_{\text {inf }}=8, \theta_{s}=15^{\circ}$ and $\theta_{i}=15^{\circ}$, with the design shock (green). Plane 3 on Figure 6. 


\section{Further Analysis}

The integration method described earlier allows us to design the shape for the second 3D compression shock after the first, forebody generated one. The shape of the generated shockwave, however, is affected when operating at off-design conditions. A number of Euler simulations were conducted to investigate the sensitivity of the resulting flowfield to off-design Mach number, angle of attack, and sideslip changes. The results are presented in Figures 8, 9, and 10 .
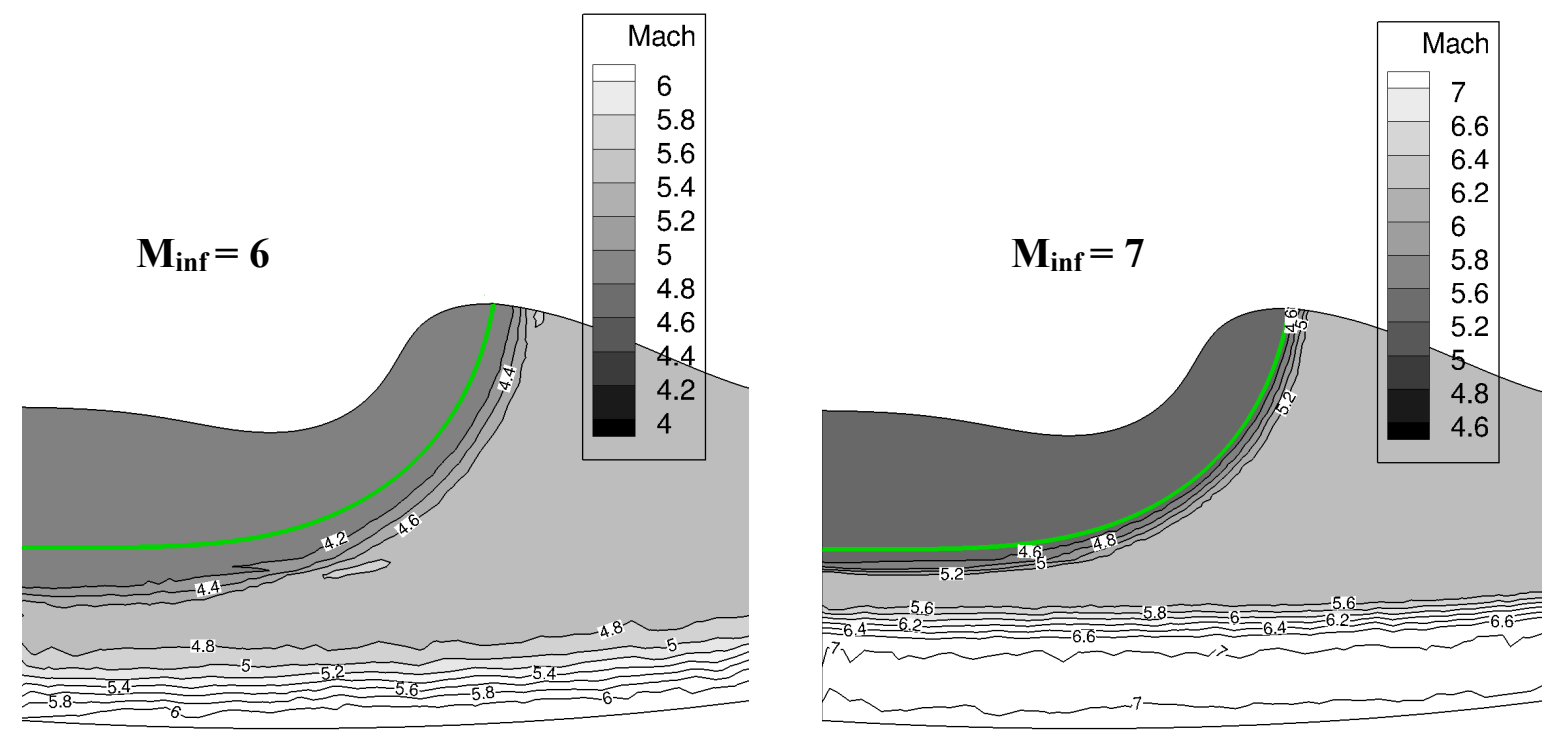

Figure 8. Mach number contours at the base plane of the $M=8$ geometry for off-design conditions, $M_{\text {inf }}=6$ left and $M_{\mathrm{in}}=7$ right with the design shockwave (green).
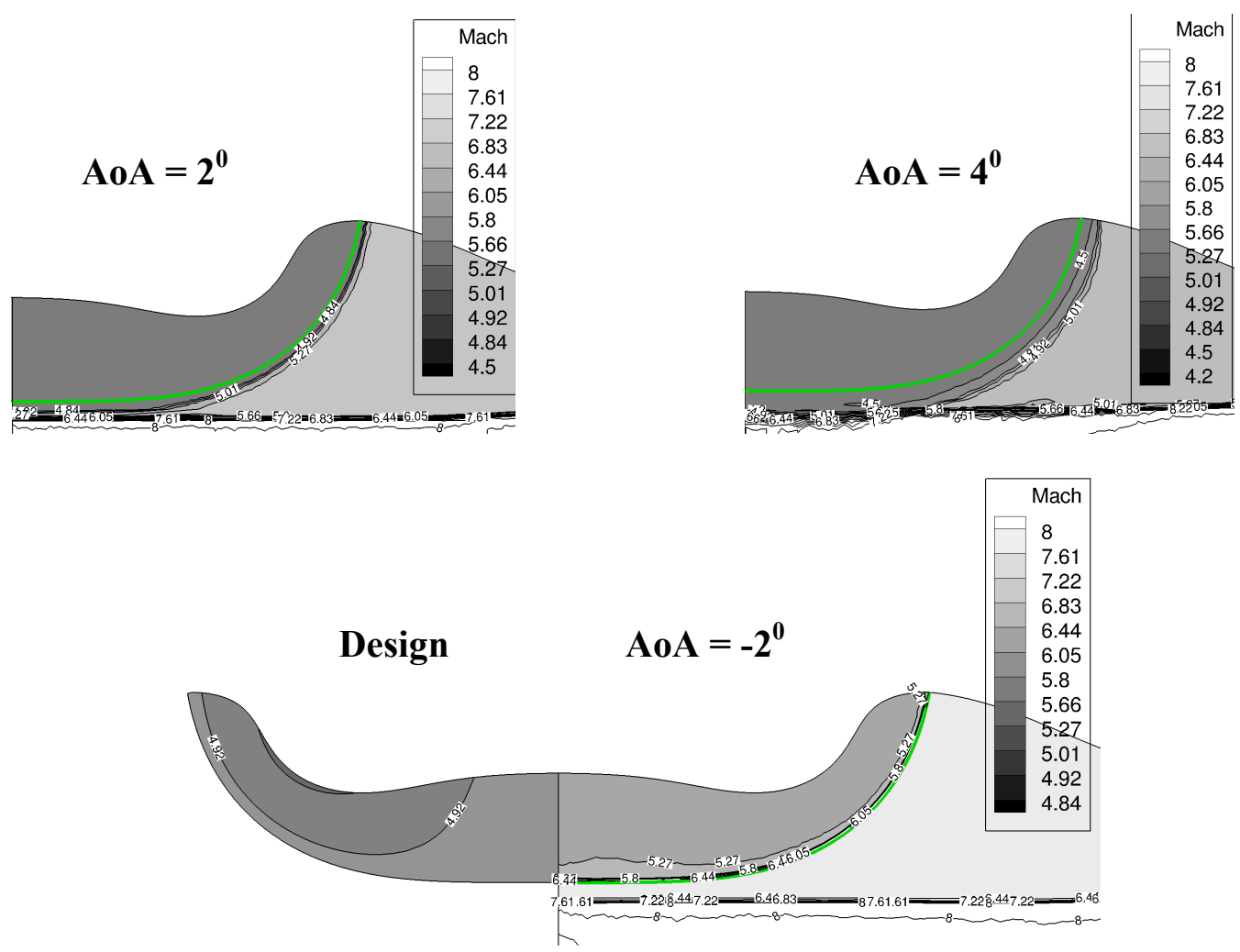

Figure 9. Mach number contours at the base plane of the $M_{\mathrm{inf}}=8$ geometry for off-design conditions, angle of attack equal to $2^{0}$ (left), $4^{0}$ (right), and $-2^{0}$ (bottom) with the design shockwave (green).

Page 6 of 11

American Institute of Aeronautics and Astronautics 
With varying Mach number and angle of attack, the flow 'seen' by the external compression geometry will still be uniform and have the same relative direction due to the nature of the forebody that creates a simple planar shock in that region. Some small disturbances may, however, be present in the osculating planes close to the edge of the planar shock region due to stronger cross-flow directed pressure gradients that may arise from the off-design behavior of the neighboring, finite radius of curvature, conical flowfield planes of the geometry. This also depends on how sharp the drop in radius of curvature is in the osculating planes close to the uniform flow region. For the moderate angles of attack and Mach number variations that we tested we did not observe any notable disturbances. The Mach number in front of the external compression geometry, $M_{1}$ in Figure 3, does change. With higher angles of attack or lower freestream Mach numbers $M_{1}$ will be lower as well, resulting in a wider shock angle generated by the external compression geometry. This, as also seen in Figures 8 and 9, results in increased spillage (assuming a cowl lip placed on the ICC), which can be beneficial from an inlet starting point of view and require simpler variable geometry, one of the advantages of mixed compression inlets ${ }^{10,14}$. Finally, Figure 10 shows the flowfield resulting from a $1^{0}$ angled sideslip of the freestream flow. In this case the flow direction in front of the external compression geometry also deviates from design conditions.

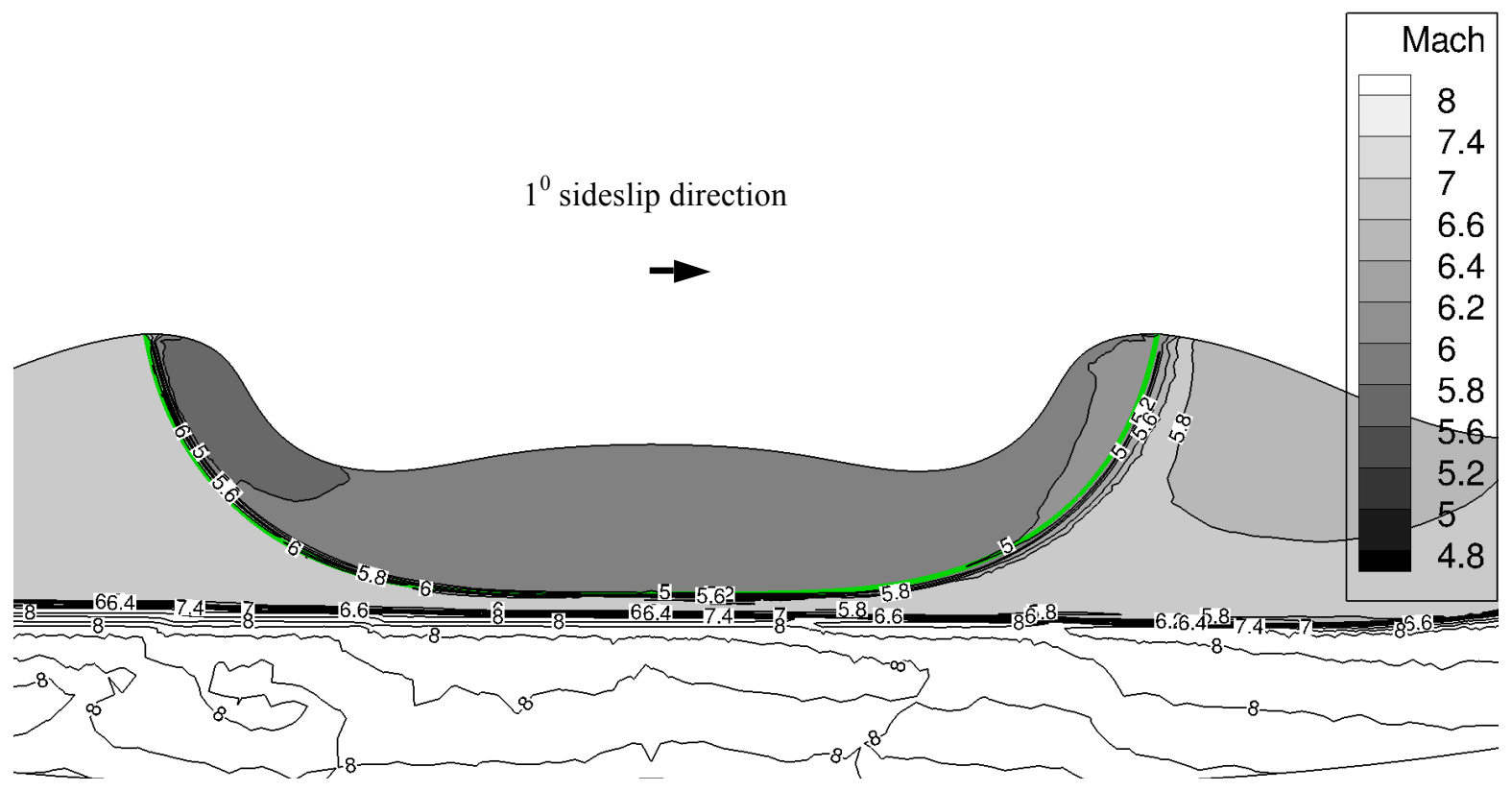

Figure 10. Mach number contour at the base plane of the $M_{i n f}=8$ geometry with $1^{0}$ sideslip of the freestream, with the design shock outline (green).

In order to illustrate the flexibility of the method described in Section III, we conclude with a depiction of example configurations that can be generated with the proposed method integrated on different forebody geometries, illustrated in Figure 11. By parametrically defining the shape of the inlet capture curve, a wide range of geometries can be generated. When attempting to maximize the capture area within the uniform region of the forebody generated flowfield and at the same time satisfy the limitations of the osculating cones method as far as the lower limits of shockwave profile radii of curvature go, the types of geometries that prevail are ones similar to the one that was examined earlier. Figure 12 illustrates a comparison of the possible capture areas of a half cone and a conical shockwave based geometry with the osculating cones generated geometry that was investigated earlier. As the aspect ratio of the section where uniform flow is available increases the osculating cones based geometry can have an even more significant advantage in potential capture area, a good example is the third geometry of Figure 11.

Designing the internal part of the inlet from that point on can be challenging, as the cross-section shape of the externally compressed flowfield at the cowl lip is not straightforward. All of its properties, however, can be rapidly calculated during the design process, as mentioned in the previous section. We discuss some of the options for designing the downstream, internal part of the mixed compression inlet that we are considering in the next section. 

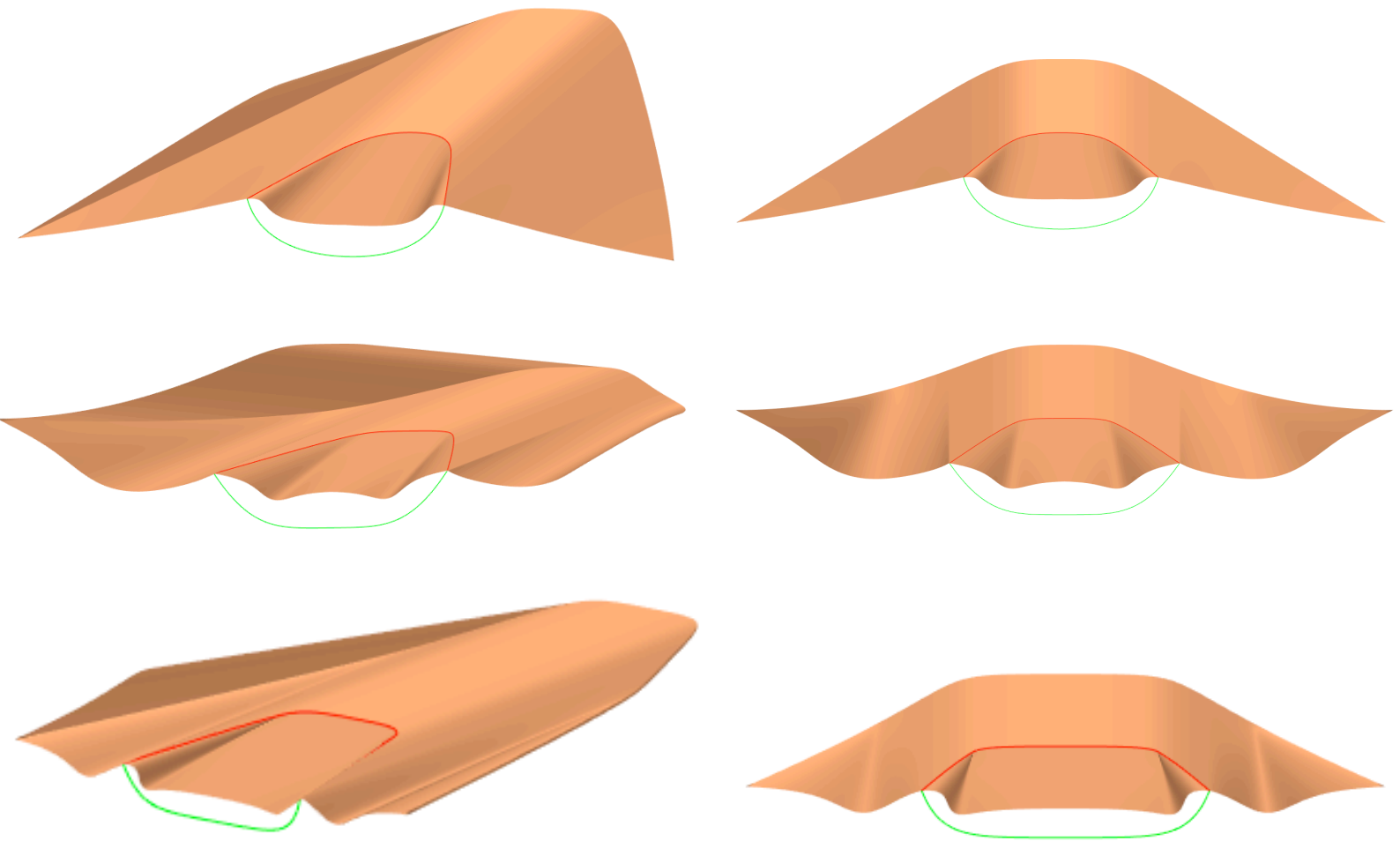

Figure 11. Example osculating cone forebody and external compression module geometries, 3D and rear views.

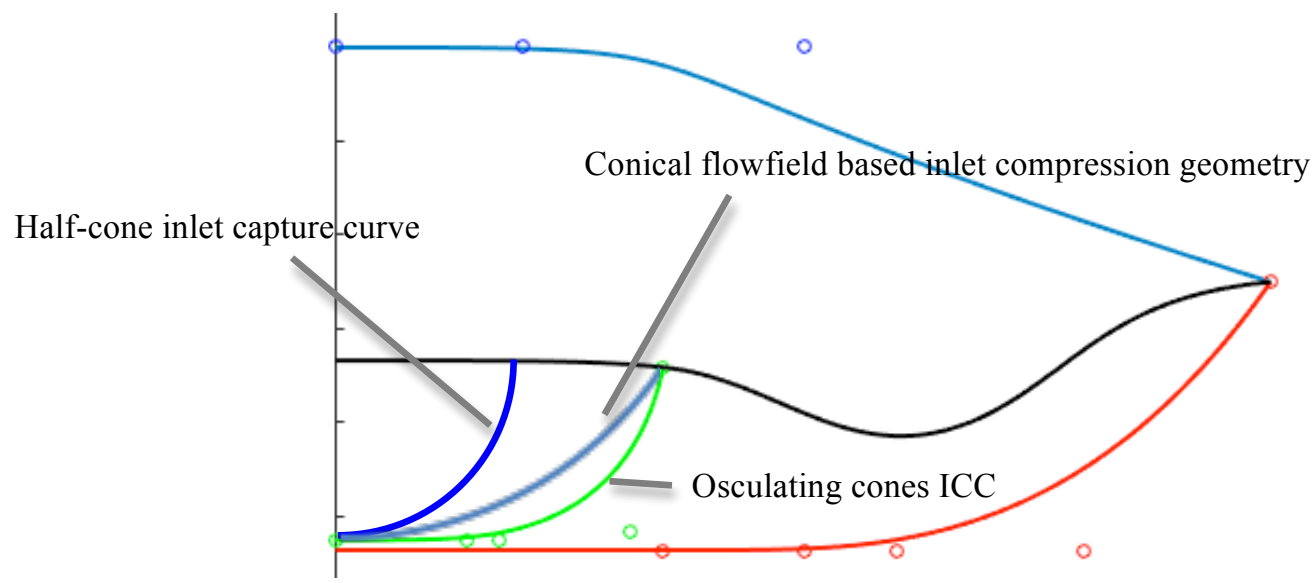

Figure 12. Capture area comparison between half-cone, conical shockwave and osculating cones compression geometries.

\section{Future Work}

Utilizing the proposed integration method we can generate the external compression part of a mixed compression inlet; the next stage is to develop the inlet duct, form the cowl lip to the isolator and combustor. A number of different options are under consideration and we briefly review them here.

One approach would be to keep designing the internal part of the inlet on the osculating planes of the external compression geometry, the same way a conical inlet is designed, possibly utilizing the method of characteristics. This is fairly straightforward but there are two issues that have to be tackled. First, the shape of the section at the end of the inlet will most likely be as complex as the section at the cowl lip, which might require further transitional 
geometry. The second is that the osculating planes are tilted relative to the freestream at an angle equal to the flow deflection angle of the forebody, and a further deflection might be necessary to redirect the flow.

Another approach that could achieve better management of the cross section shapes leading to the isolator and combustor is to utilize the externally compressed flow with more than one internal compression, isolator and combustor modules. An example with three units is shown in Figure 13.

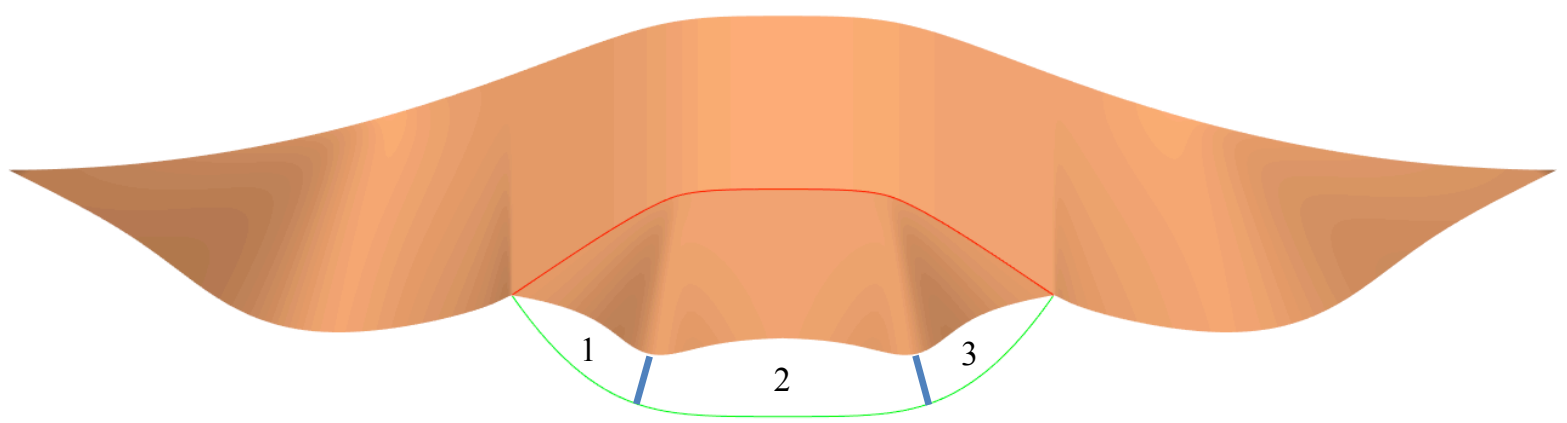

Figure 13. An example of an externally compressed flowfield that can be utilized by 3 scramjet modules.

Similarly, the osculating cones external compression geometry can be used as a $2 \mathrm{D}$ ramp that contains the mostly uniform flow at the center by compressing additional flow at the sides that is not captured by the inlet cowl, illustrated in Figure 14. While this generates additional drag when compared to a 2D ramp, the use of sidewalls and resulting viscous effects is avoided. The further compressed flow is also expected to generate lift, though not very efficiently. For the ratio of captured flow to discarded flow to be satisfactory, wide or long span geometries as that illustrated in Figure 14 would be required.

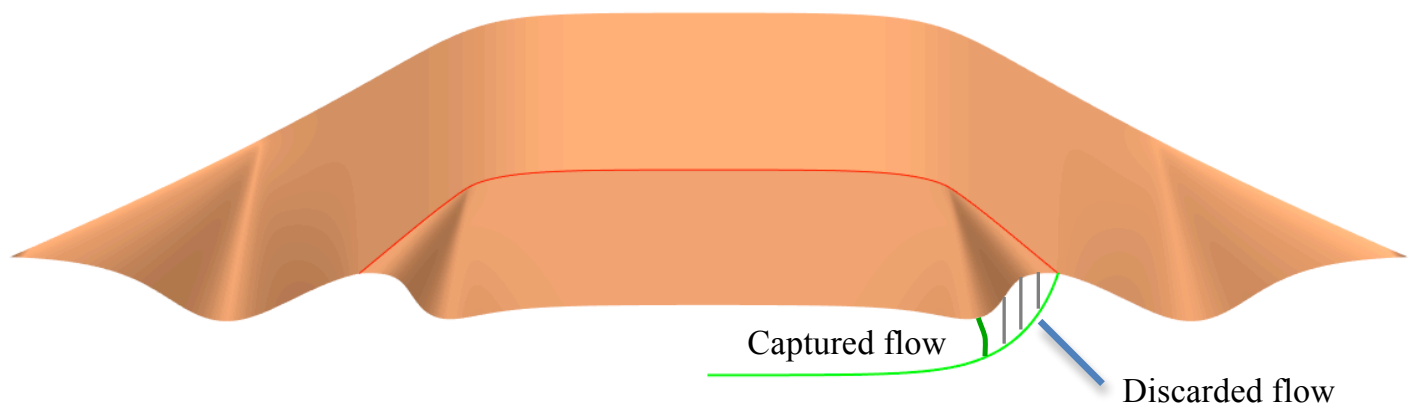

Figure 14. Utilizing only the central, more uniform part of the flowfield of the external compression geometry.

Finally, the last approach we are considering is to design the internal part of the geometry following a computational simulation based approach. A 3D transitional geometry that provides a starting point for a computational design optimization study is needed, and then direct and adjoint CFD techniques can be utilized to improve the design. An example geometry is illustrated in Figure 15. It is designed to initially deflect the flow to be parallel to the axis of the osculating cones of the external compression geometry, and then morph to an elliptical shape via a transition defined by Bernstein polynomials/Bézier curve sections. The inlet starts on design conditions but shows a number of unwanted internal shock patterns, hence providing only a starting point for a computational design approach. While this design approach can be much more expensive, it has the potential to provide much shorter geometries while allowing full control over the shape of the exit section. Another one of its disadvantages is that reaching an optimal design strongly depends on a geometry that has been partly arbitrarily designed, something that can restrict a deterministic optimization algorithm to a solution that is only locally optimal. 


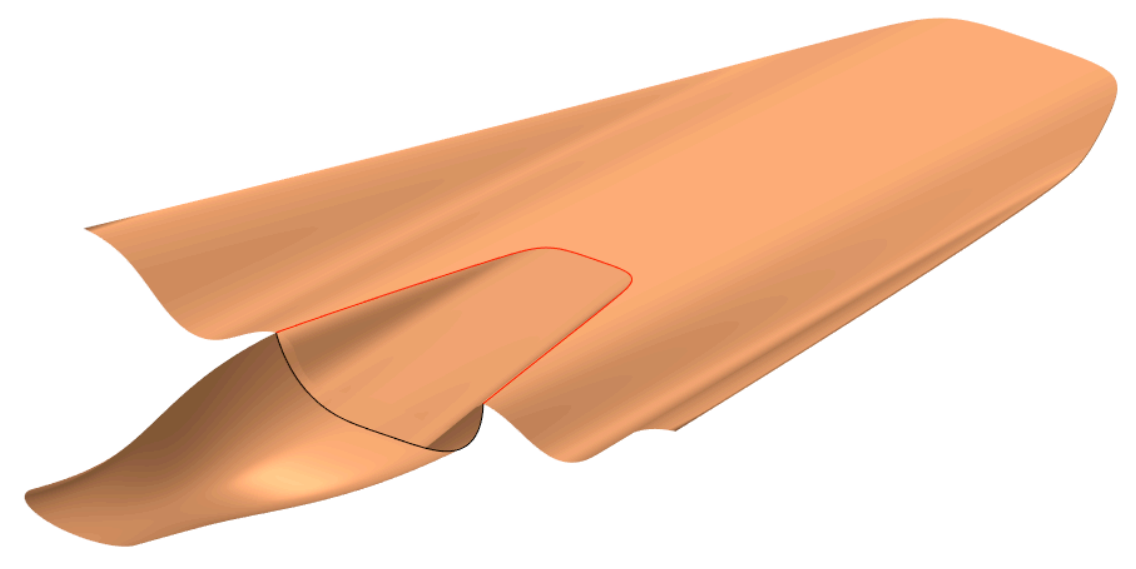

Figure 15. Internal compression geometry transitioning to an elliptical shape.

Once an internal part for the mixed compression inlet is designed, the overall efficiency of the configuration can be evaluated. Also, once a complete inviscid design is finalized, the next step is to include viscous effects in the evaluations. Finally, it is worth considering the osculating axisymmetry and osculating flowfield methods for the design of the external compression geometry, which will potentially enable more efficient compression of the flow and better control of the shape of the cowl lip section.

\section{Conclusions}

In this paper we present a method for parametrically integrating an osculating cones generated external compression geometry to an inversely designed waverider forebody. The resulting geometry can serve as the external compression part of a mixed compression inlet. The shape of the inlet capture curve can be parametrically designed to maximize the available capture area and/or shape the resulting flowfield at the cowl lip section. Additionally, the flowfield properties up to the cowl lip section can be rapidly calculated, something that can aid with the design of the downstream internal sections of the inlet. The integration approach was numerically verified with inviscid Euler simulations. Additionally, we run a number of Euler simulations for off-design conditions in order to investigate the behavior and sensitivity of the resulting flowfield to those changes. The example geometry that was investigated was found to have increased spillage (assuming a cowl lip at the inlet capture curve) at lower than design Mach numbers and increased angles of attack, as is expected of mixed compression inlets. Once the internal part of the mixed compression inlet has been designed, we will be able to evaluate the performance of the complete inlet geometries that can be generated, including investigations with viscosity taken into account.

\section{Acknowledgements}

The authors would like to acknowledge the financial support provided by MBDA UK Ltd and Innovate UK: the work reported herein has been undertaken as part of GHandI (TSB 101372), a UK Aerospace Technology Institute project.

\section{References}

${ }^{1}$ Eggers, A.J., Ashley, H., Springer, G.S., Bowles, J.V., and Ardema, M.D., "Hypersonic Waverider Configuration from the 1950's to the 1990's", AIAA Paper 93-0774, 31st Aerospace Sciences Meeting, Reno, NV, 1993.

${ }^{2}$ Nonweiler, T.R.F. (1959), “Aerodynamic Problems of Manned Space Vehicles”, Journal of the Royal Aeronautical Society, Vol. 63, pp. 521-528.

${ }^{3}$ Jones, J.G. (1963), “A method for Designing Lifting Configurations for High Supersonic Speeds Using the Flow Fields of Non-Lifting Cones”, Royal Aircraft Establishment, Report 2674.

${ }^{4}$ Rasmussen M L. (1980), "Waverider configurations derived from inclined circular and elliptic cones", J Spacecraft Rockets, 17(5): 537-545.

${ }^{5}$ Sobieczky, H., Dougherty, F., Jones, K.D., "Hypersonic Waverider Design from Given Shock Waves”, First International Hypersonic Waverider Symposium, University of Maryland, College Park, MD, 1990.

${ }^{6}$ Sobieczky, H., Zores, B., Wang, Z., Qian, Y.J., "High Speed Flow Design Using Osculating Axisymmetric Flows", Proceedings: 3rd Pacific International Conference on Aerospace Science and Technology, 1997.

Page 10 of 11

American Institute of Aeronautics and Astronautics 
${ }^{7}$ Rodi, P.E., "The Osculating Flowfield Method of Waverider Geometry Generation”, AIAA Paper 2005-0511, 44th AIAA Aerospace Sciences Meeting, Reno, NV, 2005.

${ }^{8}$ Kontogiannis, K., Sóbester, A., Taylor, N., “On the Conceptual Design of Waverider Forebody Geometries", AIAA Paper 2015-1009, 53rd AIAA Aerospace Sciences Meeting, Kissimmee, FL, 2015.

${ }^{9}$ Kontogiannis, K., Cerminara, A., Taylor, N., Sóbester, A., Sandham, N., "Parametric Geometry Models for Hypersonic Aircraft Components: Blunt Leading Edges", AIAA Paper 2015-3580, 20th AIAA International Space Planes and Hypersonic Systems and Technologies Conference, Glasgow, 2015.

${ }^{10}$ Van Wie, D. M., "Chapter 7: Scramjet Inlets", Scramjet Propulsion, editors Curran, E.T. and Murthy, S.N.B., Progress in Astronautics and Aeronautics, AIAA, Washington DC, 2001.

${ }^{11}$ Chauffour, M., "Shock-Based Waverider Design with Pressure Corrections, and Computational Simulations", MSc Thesis, University of Maryland, Department of Aerospace Engineering, 2004.

${ }^{12}$ Mill, R.W., Argrow, B.M., Center, K.B., Brauckmann, G.J., and Rhode, M.N., "Experimental Verification of the Osculating Cones Method for Two Waverider Forebodies At Mach 4 and 6," AIAA Paper 98-0682, 36th Aerospace Sciences Meeting, Reno, NV, 1998.

${ }^{13}$ Taylor, G. I., Maccoll, J. W., “The Air Pressure on a Cone Moving at High Speeds”, Proc. Roy. Soc. London A, 139, pp 279-311, 1933.

${ }^{14}$ Smart, M., “Scramjet Inlets”, RTO-EN-AVT-185, Paper 9, Rhode St. Genèse, Belgium, 2010.

Page 11 of 11

American Institute of Aeronautics and Astronautics 